https://doi.org/10.15407/ujpe63.9.790

O.K. SHUAIBOV, O.Y. MINYA, M.P. CHUCHMAN, A.O. MALININA, O.M. MALININ, V.V. DANILO, Z.T. GOMOKI

Uzhgorod National University

(54, Voloshin Str., Uzhgorod 88000,Ukraine; e-mail: alexsander.shuaibov@uzhnu.edu.ua)

\title{
PARAMETERS OF NANOSECOND OVERVOLTAGE DISCHARGE PLASMA IN A NARROW AIR GAP BETWEEN THE ELECTRODES CONTAINING ELECTRODE MATERIAL VAPOR
}

\begin{abstract}
Parameters of the nanosecond overvoltage discharge plasma in an air gap of $(1 \div 5) \times 10^{-3} \mathrm{~m}$ between the electrodes, which contains the vapor of an electrode material ( $\mathrm{Zn}, \mathrm{Cu}, \mathrm{Fe}$ ) injected into plasma due to the ectonic mechanism, have been studied. The dependences of those parameters on the ratio $E / N$ between the electric field strength $E$ and the particle concentration $N$ in the discharge are calculated for the "air-copper vapor" system, by using the numerical simulation method.
\end{abstract}

Keywords: nanosecond discharge, air, radiation emission by atoms and ions, plasma parameters, zinc, copper, iron.

\section{Introduction}

Nano- and subnanosecond high-current discharges in the air gap between metal electrodes are a source of ultraviolet (UV) radiation emitted by atoms and ions of an electrode material (copper, iron, molybdenum, tungsten, and others) in a spectral interval of 200$300 \mathrm{~nm}$ [1-5]. The vapor of an electrode material is injected into the discharge by microexplosions occurring at the surface of a needle electrode and an electrode on the basis of the sharp edge of a metal foil, as well as inhomogeneities on the surface of metal electrodes. Those microexplosions result in the appearance of ectons [6].

Unlike UV and VUV lamps with the pumping by a barrier or capacitive discharge [7, 8], "pointsource" UV lamps on the basis of a vapor of chemical elements can have very small plasma volumes

(C) O.K. SHUAIBOV, O.Y. MINYA, M.P. CHUCHMAN, A.O. MALININA, O.M. MALININ, V.V. DANILO, Z.T. GOMOKI, 2018 of about $1-5 \mathrm{~mm}^{3}$ at a pulse power of radiation emission larger than $1 \mathrm{~W}$. Therefore, they are applied to the calibration of spectral devices and various optical elements operating in the UV spectral interval. They are also promising in nanotechnology, medicine, and biology. The parameter of those "pointsource" lamps have been most completely studied, when exciting an overvoltage discharge 1-2 ns in duration, which is ignited making use of unique pump oscillators [9].

Less studied are the parameters of nanosecond discharges between metal electrodes for systems with a low inhomogeneity of the electric field strength distribution in the discharge gap [10-13]. Such conditions are created, when a system of electrodes of the "sphere-sphere" type is used, and the curvature radius of the working electrode surface is comparable with the distance between the electrodes [14].

The application of bipolar high-voltage pulses allows one to make the device more compact. Furthermore, in this case, the electrode material is spent

ISSN 2071-0194. Ukr. J. Phys. 2018. Vol. 63, No. 9 
more uniformly, when the electrode is destroyed in a strong electric field by means of microexplosions.

As far as we know from the literature, no researches have been carried out till now concerning the emission characteristics of "point-source" UV lamps on the basis of a zinc vapor. When zinc electrodes are used, plasma mainly emits in a narrow spectral interval of $200-215 \mathrm{~nm}$, which is located at the edge of the air transmission interval and is of interest for the application in medicine as a bactericidal radiation source. Since zinc has relatively low melting and evaporation temperatures, a reactor of this type can be promising for synthesizing thin nanostructured zinc oxide films [15]. Researches of such discharges make it possible to design a windowless reactor, which is a source of both the selective UV radiation and nanoparticles of transition metal oxides, including magnetic ones on the basis of iron oxides. Such devices are also promising for application in medicine and biology [16].

In works [17, 18], the results of detailed researches were reported concerning the parameters of the cathode and anode plasma formation in volumes of tens of cubic micrometers at the pre-breakdown phase of a nanosecond overvoltage discharge in the electrode system "tip-plane" filled with air under the atmospheric pressure. The electron concentration in those plasma microformations reaches a value of $(5 \div 6) \times$ $\times 10^{23} \mathrm{~m}^{-3}$. After a cathode plasma bunch has been formed and the discharge current in the gap has drastically grown, the cathode plasma bunch unites with the corresponding plasma formation, which moves from the anode. The relation between the emission parameters of plasma and the electrode materials were not quoted in the cited works.

The repetitive pulsed discharge in xenon with a microsecond pulse duration is an effective source of continuous radiation emission in a spectral interval of 120-500 nm (with a possible increase of the lamp efficiency to $20-25 \%$ at the pressure $p(\mathrm{Xe})=36 \mathrm{kPa}$ ) [19]. By increasing the xenon pressure to $1000 \mathrm{kPa}$ and exciting a nanosecond microdischarge in plasma, a diffuse discharge was obtained in the gap between tips, which emitted in a spectral interval of 200$800 \mathrm{~nm}[20]$.

The results of studies of the high-current subnanosecond discharge in gases, generation mechanisms of runaway electrons and accompanying X-rays, as well as the parameters of this plasma and the main applications of such discharges, were summarized in works [21-24]. The conditions and mechanisms of formation of homogeneous plasma aggregates with a high density and a large volume in strongly nonuniform electric fields of the high-pressure multielectrode corona discharge were considered in [25]. The main role under those conditions was played by nonlinear processes in the plasma of heavy inert gases and the effect of strong electron sticking to electronegative halogen-based molecules.

One of the promising applications of nano- and subnanosecond discharges in air can be the synthesis of nanostructures of transition metal oxides $(\mathrm{CuO}$, $\mathrm{Cu}_{2} \mathrm{O}, \mathrm{ZnO}, \mathrm{Fe}_{2} \mathrm{O}_{3}, \mathrm{Fe}_{3} \mathrm{O}_{4}$, and so forth). Nanostructures of transition metal oxides are synthesized, by using methods that are based on the deposition of nanostructures from the gas phase by thermal, laser, or magnetron sputtering. Laser methods for the nanostructure synthesis are characterized by the low yield of a final product, whereas other gas-discharge methods require the application of a vacuum equipment. The capabilities of the synthesis of transition metal oxide nanostructures in the nanosecond overvoltage discharge with the ectonic mechanism of electrode material vapor injection into a material and the nanostructure parameters have not been studied earlier. Therefore, a task to study the conditions for the synthesis of such nanostructures in atmospheric-pressure air, which would be possible making no use of expensive laser and vacuum facilities, is challenging.

In this work, the results of our research concerning the spatial, electrical, and optical characteristics of a nanosecond overvoltage discharge between the electrodes made of transition metals (zinc, copper, iron) in air and under conditions of a rather uniform electric field strength distribution in the "sphere-sphere" discharge gap are reported.

\section{Experimental Method and Equipment}

The design of a discharge chamber with a system of electrodes, between which a nanosecond discharge was ignited in air, is shown in Fig. 1. The electrodes were fabricated from zinc, copper, or stainless steel and mounted in a discharge chamber $0.03 \mathrm{~m}^{3}$ in volume fabricated from an insulator. The distance between the electrodes was $0.001-0.005 \mathrm{~m}$, so that the discharge was overvoltaged. The air pressure in the 


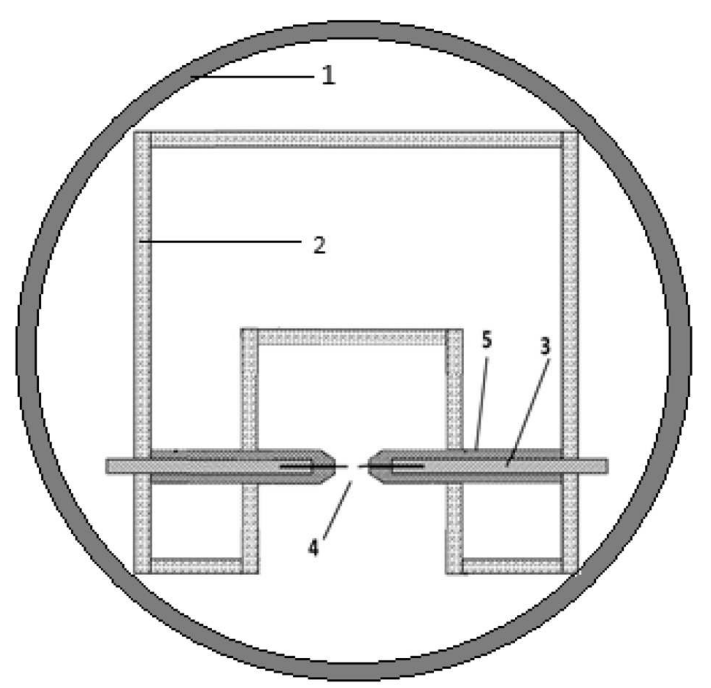

Fig. 1. Design of the gas-discharge chamber: dielectric housing (1), electrode fastening system (2), system to control the distance between the electrodes (3), metal electrodes (4), and fluoroplastic insulator (5)

chamber was varied in an interval of 6-303 $\mathrm{kPa}$. The discharge chamber was evacuated to a residual pressure of $10 \mathrm{~Pa}$, but most of the experiments were performed at an air pressure of $101 \mathrm{kPa}(1 \mathrm{~atm})$ and in the absence of the output quartz window in a discharge chamber [26, 27].

In order to reduce the electromagnetic influence on the registration system of high-current nanosecond discharge parameters, the experimental chamber with the electrode system was screened with the help of a metal mesh. The diameter of cylindrical metal electrodes was equal to $0.005 \mathrm{~m}$, and the curvature radius of the working electrode tips was $0.003 \mathrm{~m}$. Provided this relationship between the electrode curvature radius and the distance between the electrodes, the electric field strength in the gap was relatively uniform [14]. In order to localize the discharge in the gap between metal electrodes, the latter were inserted into fluoroplastic tubes, so that the length of their non-isolated sections did not exceed $0.003 \mathrm{~m}$. When the electrodes of a nanosecond discharge were used together with the dielectric tubes, an expansion of the discharge glow region was observed [28].

In order to ignite a high-current nanosecond discharge, high-voltage bipolar pulses 50-100 ns in duration and $\pm(20 \div 40) \mathrm{kV}$ in amplitude were supplied to one of the electrodes. As a result, a diffuse discharge with a peak current of 50-170 A was ignited between the ends of spherical metal electrodes. The plasma volume did not exceed $5 \times 10^{-9} \mathrm{~m}^{3}$. If the distance between the electrodes was $d=0001 \mathrm{~m}$ and the air pressure was equal to $1 \mathrm{~atm}$, the discharge gap was overvoltaged, because the electric field strength for an non-overvoltaged gap equals $0.30 \mathrm{kV} / \mathrm{m}$ at the air pressure $p=101 \mathrm{kPa}[29,30]$, whereas this parameter reached $3-5 \mathrm{kV} / \mathrm{m}$ in our experiments. The pulse repetition frequency was varied in the interval $f=40 \div 1000 \mathrm{~Hz}$.

The voltage pulses across the discharge gap and the discharge current were measured using a broadband capacitive voltage divider, a Rogowski belt, and a broadband oscilloscope 6 LOR-04. The time resolution of this registration system was $2-3$ ns. The spatial characteristics of a nanosecond discharge were studied using a digital photo camera. The discharge radiation spectra were registered making use of a monochromator MDR-2, a photomultiplier FEP-106, a DC amplifier, and an electronic potentiometer. The plasma emission was analyzed in a spectral interval of 200-650 nm. The corresponding registration system was calibrated, by using the radiation from a deuterium lamp in a spectral interval of 200$400 \mathrm{~nm}$ and from a band lamp in an interval of 400$650 \mathrm{~nm}$.

The radiation emission power of the point-source lamp was measured with the help of an ultraviolet radiometer TKA-PKM, which was tuned to measure in a spectral interval of $200-280 \mathrm{~nm}$. The radiation selection geometry was not taken into account in this case. Therefore, only the average radiation power in a given spectral interval was determined in relative units.

\section{Discharge Parameters}

Figure 2 demonstrates the registration results for the spatial characteristics of a discharge. From this figure, it follows that a spherical diffuse discharge takes place in the "sphere-sphere" system of electrodes provided the atmospheric air pressure and the distance between the electrodes to be comparable with the curvature radius of the metal electrode. The volume of this discharge strongly depends on the repetition frequency of voltage pulses. The "point-source lamp" operation mode is achieved only at the repetition fre-

ISSN 2071-0194. Ukr. J. Phys. 2018. Vol. 63, No. 9 


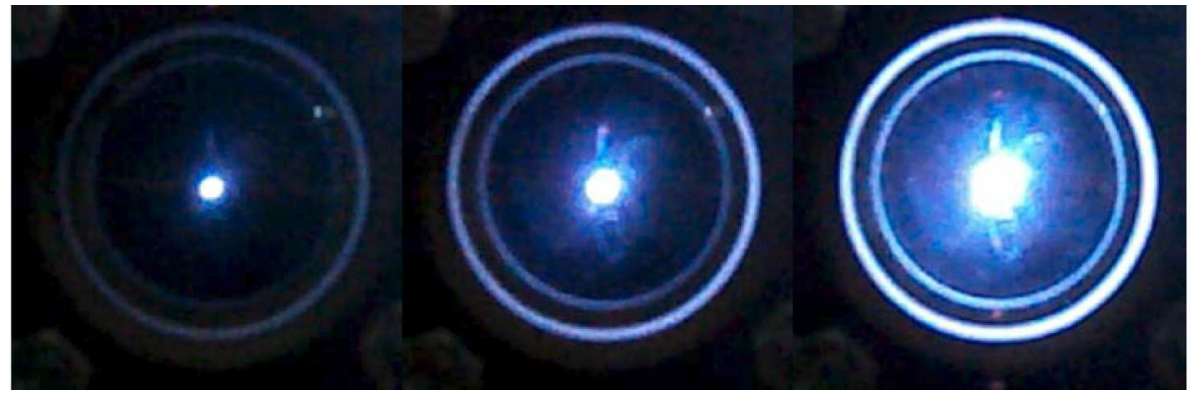

Fig. 2. Photos of a nanosecond overvoltage discharge between the copper electrodes at pulse repetition frequencies of 40,150 , and $1000 \mathrm{~Hz}$ (from left to right)

quencies of voltage pulses within an interval of 40$150 \mathrm{~Hz}$.

When the repetition frequency of voltage pulses was increased up to $1000 \mathrm{~Hz}$, the plasmoid diameter grew by 3 to 4 times and covered new areas on the working electrode surface. It can be a result of the residual phenomena in plasma, when the concentration of charged particles has no time to relax to its original level within the time interval between pulses. The spherical shape of the plasma glow region can be associated with the application of dielectric tubes on the electrodes and the accumulation of slow-moving positive ions on the insulator surface, which are formed as a result of the ionization processes near the electrodes and change the configuration of the electric field strength in the interelectrode gap [28]. The second cause for this phenomenon can be the specific features of the streamer formation in strongly overvoltaged gaps of a nanosecond discharge in air The streamers are generated in the direction perpendicular to the interelectrode gap and the electric field strength vector [9].

The diffuse character of the examined discharge at the atmospheric air pressure is confirmed by the results of researches of the spatial parameters of the transverse nanosecond discharge making no use of a special preionization system, when the discharge was ignited in nitrogen at the pressures $p=4 \div 101 \mathrm{kPa}$ taking advantage of a high-voltage modulator with the voltage pulse amplitude $U<35 \mathrm{kV}$ [31]. The photos of this discharge together with the registration data of the discharge spatial characteristics making use of a CCD camera showed that the diffuse form of such discharges is retained during the whole voltage pulse at various repetition frequencies. The experimental results [31] testify that a beam of run- away electrons is formed in the strongly overvoltaged nanosecond discharge in nitrogen, only if the nitrogen pressure does not exceed $13 \mathrm{kPa}$. Therefore, under the available experimental conditions, the main factor determining the diffuse character of the discharge is the $\mathrm{X}$-ray radiation emitted by plasma.

The diffuse character of a plasmoid and its shape close to spherical were similar to those in the photos of nanosecond discharges in air at the distance between the electrodes $d<0.005 \mathrm{~m}$ and their curvature radius of $0.006 \mathrm{~m}$ [29]. The spherical form of the plasmoid can result from the generation of accompanying characteristic and bremsstrahlung X-ray radiation in the strongly overvoltaged discharge gap [30,32-34], which isotropically illuminates the entire gap. According to data of recently published work [31], a beam of runaway electrons in atmosphericpressure air and under experimental conditions close to ours can be formed, only if the air pressure does not exceed $13.3 \mathrm{kPa}$. Therefore, the main factors governing the uniformity of the nanosecond overvoltage discharge, which was studied by us, were the characteristic radiation (the $\mathrm{X}$-ray spectral lines emitted by the metal atoms and the nitrogen atom at the excitation of their inner shells) and the bremsstrahlung $\mathrm{X}$-ray radiation from the anode.

Because of the mismatch between the output resistance of a high-voltage modulator and the discharge impedance, as well as the presence of pulses reflected from the discharge gap with plasma, a voltage pulse consisted of a few small peaks each about 5-10 ns in duration. The duration of the main part of a voltage pulse train reached 50-100 ns. Small bipolar peaks of the voltage pulse had the amplitudes of the positive and negative components up to $15-20 \mathrm{kV}$. The current pulses of the nanosecond discharge consisted of 


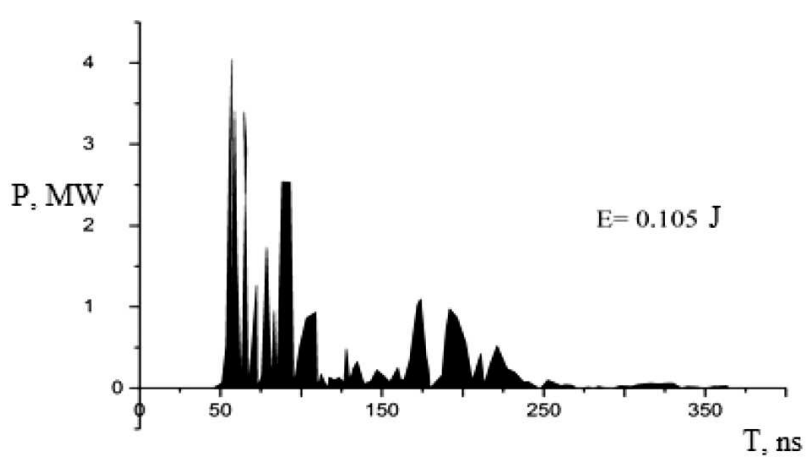

Fig. 3. Pulse power of a nanosecond overvoltage discharge in air between copper electrodes $(p=101 \mathrm{kPa}, f=100 \mathrm{~Hz})$

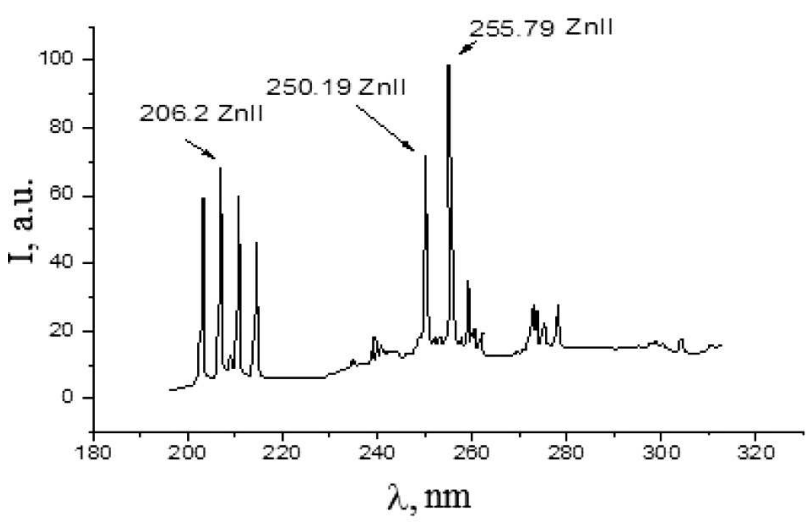

Fig. 4. Plasma radiation emission spectrum of a nanosecond overvoltage discharge in air at $p=101 \mathrm{kPa}$. The interelectrode distance $d=0.001 \mathrm{~m}$

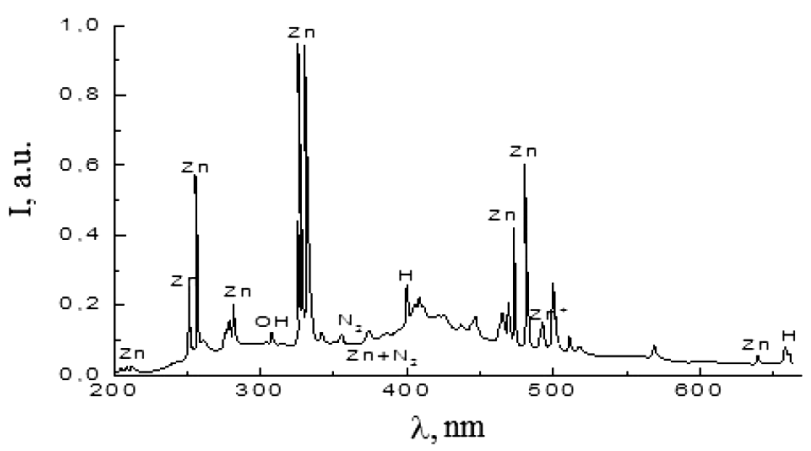

Fig. 5. Plasma radiation emission spectrum of a discharge in the mixture air $(p($ air $)=101 \mathrm{kPa})+$ water vapor $\left(p\left(\mathrm{H}_{2} \mathrm{O}\right)=\right.$ $=130 \mathrm{~Pa})$. The interelectrode distance $d=0.005 \mathrm{~m}$

a sequence of bipolar current pulses with the amplitudes of the positive and negative components equal to 120-150 A. The total duration of the sequence of current pulses with an amplitude decreasing in time reached 150-200 ns. Such a character of the pulsed energy contribution, which occurs at the mismatch between the output resistance of a high-voltage generator of nanosecond pulses and the discharge plasma impedance, favors the effective sputtering of the electrode material.

The spatial, electrical, and some emission parameters of the bipolar nanosecond discharge between metal electrodes $(\mathrm{Zn}, \mathrm{Cu}$, and $\mathrm{Fe}$ at $d=0.5 \div 4 \mathrm{~mm}$ ) in the nitrogen atmosphere at a pressure of 1 atm were studied in works $[12,13]$. The results obtained there correlate with the results of our experiments.

By multiplying the corresponding data taken from the pulse current oscillogram and the voltage oscillogram, the time distribution of the pulse energy contribution to the nanosecond discharge plasma was calculated. The maximum of the discharge pulse power was observed at the initial stage of the discharge gap breakdown and reached a value of $4 \mathrm{MW}$ (Fig. 3). The integration of the pulse power over the time allowed us to determine the electric energy that was introduced into the discharge plasma during a single sequence of voltage and current pulses. Under the ignition conditions of a nanosecond discharge at an air pressure of $101 \mathrm{kPa}$ and the interelectrode gap width $d=0.001 \mathrm{~m}$, the energy introduced into plasma was equal to $105 \mathrm{~mJ}$ (Fig. 3). When the electrodes made of zinc or a stainless steel were used instead of copper electrodes, the electrical characteristics of a discharge in air at the atmospheric pressure did not change considerably.

The research of the spectral characteristics of radiation emission by plasma of a highccurrent nanosecond discharge in atmospheric-pressure air between the electrodes fabricated from transition metals ( $\mathrm{Zn}$, $\mathrm{Cu}, \mathrm{Fe}$ ) showed that about $80-90 \%$ of the emitted power in a spectral interval of $200-650 \mathrm{~nm}$ were concentrated in a spectral interval of $200-220 \mathrm{~nm}$ for $\mathrm{Zn}$ electrodes, 200-230 nm for $\mathrm{Cu}$ electrodes, and 200$260 \mathrm{~nm}$ for Fe electrodes. When identifying the spectral lines in the radiation spectra of discharges, reference books $[35,36]$ were used.

In Figs. 4 and 5, the emission spectra of the nanosecond overvoltage discharge in air and in a mixture of air with a small admixture of water vapor (water vapor was added to obtain radiation spectra with the diagnostic spectral lines of a hydrogen atom), respectively, obtained at various distances between zinc electrodes. At a significant overvolt- 
age across the discharge gap, when the distance between the electrodes is minimum $(d=0.001 \mathrm{~m})$, and in atmospheric-pressure air, two groups of intensive spectral lines emitted by the zinc atom and the zinc ion in a spectral interval of $200-280 \mathrm{~nm}$ dominate in the plasma radiation spectra. The most intense spectral lines in group $\mathrm{Zn}$ II were the ionic spectral lines at 202.6 and $206.2 \mathrm{~nm}$. In group Zn I, these were the atomic spectral lines at 250.2 and $255.8 \mathrm{~nm}$. Those data correlated well with the spectral parameters of a lamp [37]. In comparison with the data of work [37], the UV radiation spectrum in those intervals included much more intense spectral lines of zinc.

As the distance between the electrodes was increased to $d=0.005 \mathrm{~m}$ (whereas the air pressure remained constant), the electric field strength in the discharge gap decreased, which led to a decrease of the electron temperature and worsened the conditions of X-ray preionization. The intensity of the spectral lines emitted by zinc atoms and ions in a spectral interval of $200-215 \mathrm{~nm}$ practically vanished, and the intensity of the atomic spectral lines of zinc in an interval of $250-280 \mathrm{~nm}$ became several times lower. For the plasma of air with small admixtures of zinc vapor and at $d=0.005 \mathrm{~m}$, the spectral lines of zinc in wavelength intervals of 250-280, 330-350, and 460-510 nm became the most intense. If a small admixture of water vapor $(p=130 \mathrm{~Pa})$ was added to air at the atmospheric pressure (see Fig. 6), the radiation spectrum of the discharge demonstrated the low-intensity band of a hydroxyl radical $\mathrm{OH}$ at $309.3 \mathrm{~nm}$ and the spectral lines of the hydrogen atom in the visible spectral interval.

In the radiation spectrum of the plasma of a mixture of air, water vapor, and zinc vapor, a wide band was registered in a spectral interval of 370$470 \mathrm{~nm}$. This band is not observed in the radiation spectrum of plasma with helium instead of air. The maximum of this band is located in a spectral interval of 410-415 nm. This band can belong to molecules or small clusters on the basis of zinc oxides, which are excited in the gas phase. Those broad bands correlate well with the luminescence bands of nanostructures on the basis of zinc oxide [38].

Figure 6 exhibits the radiation spectra of nanosecond discharge plasma in air at the pressures $p=101$ and $303 \mathrm{kPa}$ between copper electrodes in the spectral interval $\lambda=200 \div 230 \mathrm{~nm}$. As was in the case of

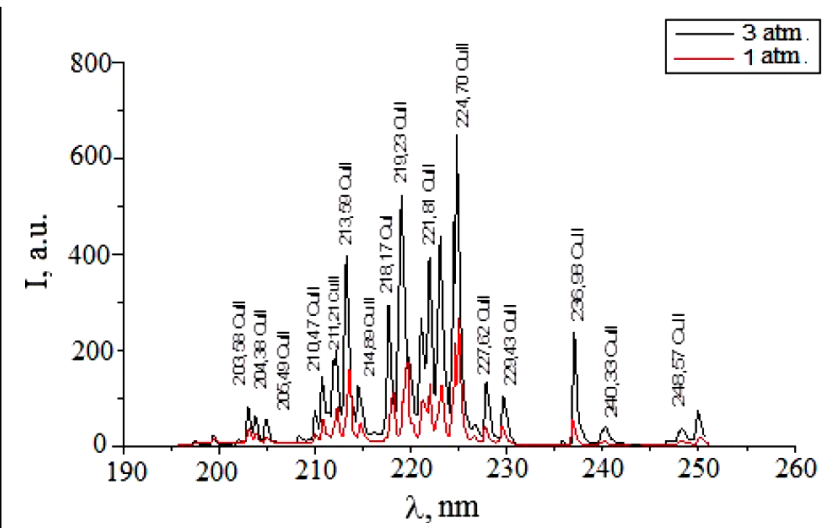

Fig. 6. Interval of the plasma emission spectrum of a nanosecond overvoltage discharge between copper electrodes in air at pressures of 101 and $303 \mathrm{kPa}$ containing the most intense spectral lines of copper atoms and ions. The interelectrode distance $d=0.001 \mathrm{~m}$. The pulse repetition frequency $f=40 \mathrm{~Hz}$

less powerful unipolar nanosecond discharges between copper electrodes [3], the spectral lines of copper ions dominate. The obtained spectrum of UV radiation also correlates well with the radiation spectrum of the unipolar subnanosecond discharge with a beam of runaway electrons at a distance of $0.0005 \mathrm{~m}$ between copper electrodes [2]. In the radiation spectra, the most intense are lines corresponding to transitions from the energy levels of singly charged copper ions (8.23-9.12 eV) occurring at the change of electron configuration $4 p-4 s$, as well as the spectral lines of copper atoms, which correspond to transitions from highly excited states of a copper ion with energies in an interval of $5.68-7.02 \mathrm{eV}$.

Figure 7 illustrates a section of the radiation spectrum of nanosecond discharge plasma between the stainless steel electrodes that contains the most intense spectral lines. In Table, the identification of the most intensive spectral lines of iron in a spectral interval of $200-300 \mathrm{~nm}$ is presented. The deciphering of the spectrum showed that, in the case of a discharge between stainless steel electrodes, the spectral lines of iron atoms and singly charged iron ions dominate, with the spectral line $249.6 \mathrm{~nm}$ FeI being the most intense. Our results correlate well with the corresponding emission spectra of a high-voltage subnanosecond discharge in atmospheric-pressure air registered in the "needle-plane" electrode geometry at $d=0.012 \mathrm{~m}$, when runaway electrons play a significant role [39]. 


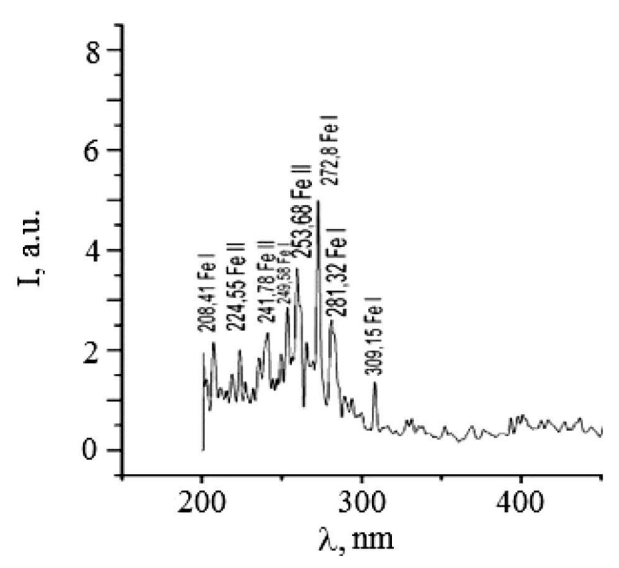

Fig. 7. Emission spectrum of the nanosecond discharge plasma between stainless steel electrodes. The air pressure equals $101 \mathrm{kPa}$, the interelectrode distance $d=0.003 \mathrm{~m}$, the pulse repetition frequency $f=40 \mathrm{~Hz}$

In the radiation spectrum of a discharge between a copper and a stainless steel electrode, as well as in the case of a discharge between two copper electrodes, the radiation intensity was maximum for the transitions of singly charged copper ions in a spectral interval of $210-220 \mathrm{~nm}$, and the spectral lines of iron only complemented this spectrum in an interval of 250-300 nm. The most intense of the iron spectral lines was the line $271 \mathrm{~nm}$ FeI. This distribution of the discharge radiation emission between the copper and stainless steel electrodes is mainly associated with different thermophysical properties of indicated metals.

The emission of iron spectral lines in wavelength intervals of $360-400$ and $700-730 \mathrm{~nm}$ by plasma of a nanosecond discharge in high-pressure helium $(p=$

Identification of the spectrum emitted by the nanosecond discharge plasma in air between the stainless steel electrodes $(p=101 \mathrm{kPa}, d=0.003 \mathrm{~m}$, and $f=40 \mathrm{~Hz})$

\begin{tabular}{|c|l|r|r|c|}
\hline$\lambda, \mathrm{nm}$ & Object & $I$, rel. un. & $\begin{array}{c}\text { Lower } \\
\text { level }\end{array}$ & $\begin{array}{c}\text { Upper } \\
\text { level }\end{array}$ \\
\hline 208.41 & Fe I & 100 & $\mathrm{a}^{5} \mathrm{D}$ & $\mathrm{v}^{5} \mathrm{P}^{0}$ \\
224.55 & Fe II & 300 & $\mathrm{z}^{6} \mathrm{D}^{0}$ & $\mathrm{e}^{6} \mathrm{~F}$ \\
241.78 & Fe II & 60 & $\mathrm{~b}^{2} \mathrm{H}$ & $\mathrm{y}^{2} \mathrm{H}^{0}$ \\
249.58 & Fe I & 10000 & $\mathrm{a}^{5} \mathrm{~F}$ & $\mathrm{w}^{5} \mathrm{G}^{0}$ \\
253.68 & Fe II & 2000 & $\mathrm{a}^{4} \mathrm{H}$ & $\mathrm{z}^{4} \mathrm{H}^{0}$ \\
272.80 & Fe I & 4000 & $\mathrm{a}^{4} \mathrm{D}$ & $\mathrm{z}^{4} \mathrm{D}^{0}$ \\
309.15 & Fe I & 120 & $\mathrm{~b}^{2} \mathrm{~F}$ & $\mathrm{z}^{2} \mathrm{~F}^{0}$ \\
\hline
\end{tabular}

$=101 \div 505 \mathrm{kPa})$ between stainless electrodes $(d=$ $=0.012 \mathrm{~m}$ ) at an overvoltage of $100-300 \%$ was observed in work [40]. The spectral interval corresponding to shorter wavelengths was not examined in the cited work. Iron atoms were found to emit the most intensively in the high-current diffuse discharge regime, when bright cathode spots were observed on the cathode surface. In air, the high-current diffuse discharge is not ignited.

The dependence of the average power of the UV radiation emission by a nanosecond discharge in a spectral interval of 200-280 $\mathrm{nm}$ on the voltage pulse repetition frequency was nonlinear. Its maximum growth was observed in a pulse repetition frequency interval of $40-350 \mathrm{~Hz}$. As this parameter was increased from 35 to $1000 \mathrm{~Hz}$, the average power of the UV radiation emission by the discharge grew by about an order of magnitude. At the same time, the increase of the charging voltage of the working condenser from 13 to $20 \mathrm{kV}$ (at $f=35 \mathrm{~Hz}$ ) gave rise to the increase of the UV radiation power emitted by a discharge by only a factor of two [5]. The obtained results testify that, in order to increase the average power of the UV radiation emitted by a discharge, the most promising way consists in increasing the voltage pulse repetition frequency.

Under the conditions of described experiments, the ectonic mechanism (the explosion of micropoints on the electrode surface) dominates in the injection of metal vapor into plasma. The corresponding electron concentration in plasma can reach a value of $10^{16}$ $10^{17} \mathrm{~cm}^{-3}$ [24]. Therefore, the mechanism of appearance of excited metal ions can be governed by the excitation processes of metal ions in the ground state by electrons, and by electron-ion recombination processes. The corresponding effective cross-sections for copper and iron ions are not known at present. The corresponding effective cross-sections for zinc ions have been studied, and they were found to be quite large, namely, $10^{-16} \mathrm{~cm}^{2}$ [41]. Therefore, it is quite probable that excited atoms and ions of transition metals are formed in the plasma of a nanosecond overvoltage discharge by exciting the singly charged ions of those metals in the ground-energy state by electrons and owing to the recombination process of the doubly charged ions of transition metals by discharge electrons.

The plasma that is dealt with in this work is a complicated object for theoretical studies and even for 
numerical evaluations, because it contains complex clusters of transition metal oxides and solid microand nanoparticles. Thin nanostructured copper oxide films were synthesized on a glass substrate mounted near the discharge. Some spatial and optical parameters of those nanostructures were reported in our work [42].

\section{Plasma Parameters}

The simulation of plasma parameters was carried out for a nanosecond discharge in atmosphericpressure air between copper electrodes. Copper vapor was injected into plasma due to the electrode erosion. As was done in work [41], where the plasma in atmospheric-pressure air with small admixtures of copper vapor was investigated and where the partial pressure of copper vapor was estimated to equal $0.1 \%$, the partial pressure of copper vapor for our estimates was chosen to equal $100 \mathrm{~Pa}$. Under the given experimental conditions, the maximum value of the $E / P$ parameter reached a value of about $530 \mathrm{~V} /(\mathrm{cm}$ torr $)$, which is less than the critical $E / P$ value for nitrogen according to the local criterion of electron escape, $590 \mathrm{~V} /$ (cm torr) [30]. Therefore, when simulating the parameters of plasma in atmospheric-pressure air with small admixtures of copper vapor, the standard soft code for solving the Boltzmann kinetic equation to determine the electron energy distribution function [43] was chosen. Unlike similar codes of the BOLCING and BOLCING ${ }^{+}$types, which allow the simulation to be carried out only for three chemical elements, the code used by us makes it possible to simulate mixtures of five different components. As a result, the influence of the real air composition on the plasma parameters can be taken into account more completely.

On the basis of the calculated electron energy distribution function, the average energy and mobility of electrons, the specific losses of the discharge power in various electronic processes, and the rate constants of elastic and inelastic electron scattering by copper and argon atoms, and carbon dioxide, oxygen, and nitrogen molecules, as well as their dependences on the reduced electric field (the ratio between the electric field strength $E$ and the total concentration $N$ of copper vapor and gases entering the atmosphere) were determined. The ratio between the indicated components in atmospheric-pressure air

ISSN 2071-0194. Ukr. J. Phys. 2018. Vol. 63, No. 9 was equal to $0.8: 7.0984: 0.266: 159.197: 593.438$, respectively. The parameter $E / N$ was varied within an interval of 1-1300 Td, which included the experimental values. The set of cross-sections for electronic processes, which were made allowance for in the simulation, and the basic expressions for calculated plasma parameters are given in the code manual [44].

The average energy of electrons in the discharge increased almost linearly from 0.15 to $29.1 \mathrm{eV}$, as the parameter $E / N$ grew from 1 to $1300 \mathrm{Td}$. In the experimental interval of the reduced electric field strength 615-820 Td, in which the electrical and optical characteristics of the discharge were studied, the average electron energy varied from 12.5 to $16.0 \mathrm{eV}$. The electron temperature increased from 145000 to $185600 \mathrm{~K}$, respectively.

According to the results of numerical simulations, the product of the electron mobility and the total concentration of atoms and molecules in the gas mixture changes from $0.7458 \times 10^{24} N$ to $0.6893 \times 10^{24} N$ (in $\mathrm{m}^{-1} \mathrm{~V}^{-1} \mathrm{~s}^{-1}$ units), when the parameter $E / N$ is varied in an interval of $615-820 \mathrm{Td}$, which leads to the change of the electron drift velocity from $4.58 \times 10^{5}$ to $5.65 \times 10^{5} \mathrm{~m} / \mathrm{s}$, provided an electric field strength of $(15.0 \div 20.0) \times 10^{6} \mathrm{~V} / \mathrm{m}$ in plasma. The corresponding values of the electron concentration fall within an interval of $(10.4 \div 8.5) \times 10^{21} \mathrm{~m}^{-3}$ at a current density of $765 \times 10^{6} \mathrm{~A} / \mathrm{m}$ at the electrode surface $\left(0.196 \times 10^{-6} \mathrm{~m}^{2}\right)$. The calculated electron concentration correlated well with the maximum of the experimentally determined electron concentration in an arc discharge between different composite electrodes, including copper-based ones $\left(N_{e}=\right.$ $=10^{22} \mathrm{~m}^{-3}$ ) [45].

The maximum specific losses of the discharge power for inelastic electron processes in the discharge in a mixture of copper vapor with air were observed for a nitrogen molecule and reached $32.7 \%$ in the case of excitation of the set of singlet states of a nitrogen molecule at a reduced electric field strength of $820 \mathrm{Td}$. For the copper atom, the specific power losses of the discharge reached a maximum value of $2.9 \%$ at the excitation of its resonant state ${ }^{2} \mathrm{P}_{3 / 2,1 / 2}$ at $E / N=135 \mathrm{Td}$. At a reduced electric field strength of $615 \mathrm{Td}$, they amounted to $1 \%$, and, at a reduced field strength of $820 \mathrm{Td}$, they decreased to $0.8 \%$. With the increase of the parameter $E / N$ to $1300 \mathrm{Td}$, the specific power losses in the discharge reached a maximum 


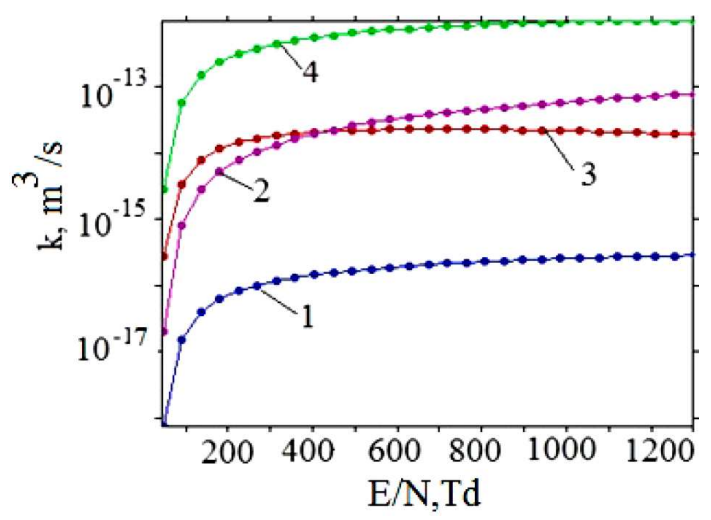

Fig. 8. Dependences of the rate constants of electron collisions with copper atoms on the $E / N$ parameter for the plasma in a mixture of copper vapor $(100 \mathrm{~Pa})$ and air $(101 \mathrm{kPa})$ (the total pressure of the mixture $p=101.1 \mathrm{kPa}$ ): excitation of the ${ }^{4} \mathrm{~F}_{7 / 2}$ state of a copper atom $\left(E_{\mathrm{thr}}=5.10 \mathrm{eV}\right)(1)$, ionization of a copper atom (2), excitation of the metastable state of copper atom $\left({ }^{2} \mathrm{D}_{5 / 2}\right)(3)$, and excitation of the resonance state of a copper atom $\left({ }^{2} \mathrm{P}_{3 / 2}\right)(4)$

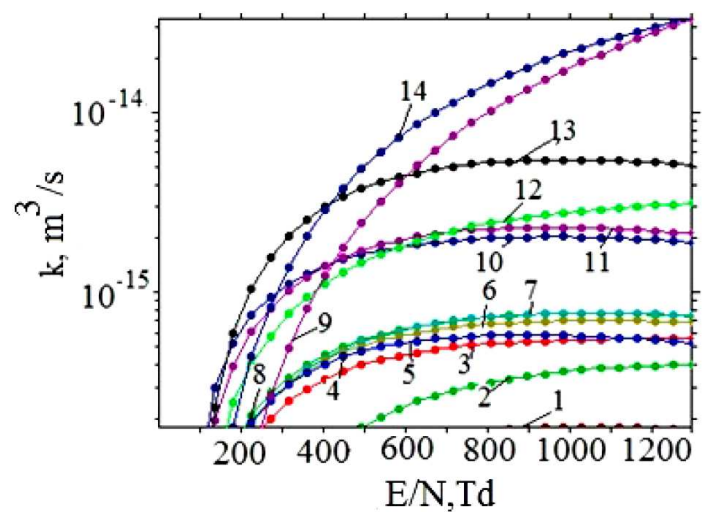

Fig. 9. Dependences of the rate constants of electron collisions with nitrogen molecules on the parameter $E / N$ for the discharge in a mixture of copper vapor and air: excitation of state $\mathrm{E}^{3}(1)$, excitation of state $\mathrm{A}^{3}, v=0 \div 4$ (2), excitation of state $\mathrm{a}^{\prime \prime 1}(3)$, excitation of state $\mathrm{a}^{\prime 1}(4)$, excitation of state $\mathrm{A}^{3}$, $v=5 \div 9(5)$, excitation of state $\mathrm{B}^{\prime 3}(6)$, excitation of state $\mathrm{w}^{1}$ $(7)$, excitation of state $\mathrm{a}^{1}(8)$, ionization of nitrogen molecules by electrons $(9)$, excitation of state $\mathrm{B}^{3}(10)$, excitation of state $\mathrm{W}^{3}(11)$, excitation of state $\mathrm{a}^{1}(12)$, excitation of the state $\mathrm{C}^{3}$ (13), and excitation of the set of singlet states of a nitrogen molecule (14)

value of $40.2 \%$ for the process of nitrogen molecule ionization by electrons.

Figure 8 demonstrates the results of numerical calculations for the dependences of the rate constants of electron collisions with copper atoms on the $E / N$ parameter in a discharge in the mixture of copper vapor with the air $[p(\mathrm{Cu})=100 \mathrm{~Pa}, p($ air $)=$ $=101 \mathrm{kPa}$. The rate constants are characterized by large values, $k \approx 10^{-17} \div 10^{-12} \mathrm{~m}^{3} / \mathrm{s}$. This fact is associated with large effective cross-sections of corresponding processes. In an interval of $615-820 \mathrm{Td}$ for the reduced electric field strength, the excitation rate constants for the ${ }^{2} \mathrm{P}_{3 / 2,1 / 2},{ }^{2} \mathrm{D}_{3 / 2},{ }^{2} \mathrm{D}_{5 / 2}$, and ${ }^{4} \mathrm{~F}_{7 / 2}$ states of a copper atom and its ionization are within intervals of $(7.4 \div 8.6) \times 10^{-13},(0.29 \div 0.28) \times$ $\times 10^{-13},(0.23 \div 0.22) \times 10^{-13},(0.20 \div 0.23) \times 10^{-15}$, and $(0.34 \div 0.46) \times 10^{-13} \mathrm{~m}^{3} / \mathrm{s}$, respectively.

The results of numerical calculations carried out for the dependence of the rate constants for electron collisions with nitrogen molecules in a discharge in the mixture of air and copper vapor are shown in Fig. 9. In an interval of $615-820$ Td for the reduced electric field strength, the excitation rate constants for the electron states of a nitrogen molecule were found to be within intervals of $5.5 \times 10^{-17}$ $0.86 \times 10^{-14} \mathrm{~m}^{3} / \mathrm{s}$ (at $E / N=615 \mathrm{Td}$, the states corresponding to curves $1-14$ ) and $6.4 \times 10^{-17}$ $1.5 \times 10^{-14} \mathrm{~m}^{3} / \mathrm{s}$ (at $E / N=820 \mathrm{Td}$, the states corresponding to curves 1-14). A maximum value of $1.5 \times 10^{-14} \mathrm{~m}_{3} / \mathrm{s}$ for the excitation rate constant was observed at a reduced electric field strength of $820 \mathrm{Td}$ in the case of excitation of a set of singlet-singlet states of a nitrogen molecule with an energy threshold of $13 \mathrm{eV}$.

Large values of excitation constants for the lower electron states of a nitrogen molecule confirm their significant role in the population of the upper energy levels of a copper ion that participate in the formation of the radiation emission by copper plasma in a spectral interval of 200-250 $\mathrm{nm}$. For instance, as was found in work [46], a long-term (for about $2 \mathrm{~ms}$ ) luminescence of copper atoms was observed in a subnanosecond discharge in a mixture of nitrogen and air at the atmospheric pressure between copper electrodes, which exceeded the discharge current duration by three orders of magnitude. The long-term glow of copper atoms can be associated with the resonance energy transfer from the metastable state $A^{3} \Sigma_{u}^{+}$of a nitrogen molecule to the $3 d^{10} 4 d$ level of a copper atom. As a result, a quasimetastable state is formed in a copper atom, through which an effective step ionization of copper atoms with the formation of $\mathrm{Cu}^{+}$and $\mathrm{Cu}^{++}$ions in the ground state can take place. This fact is important for the population of up- 
per energy levels of $\mathrm{Cu}$ ions at the electron excitation of $\mathrm{Cu}^{+}(0)$ ions and at the recombination of $\mathrm{Cu}^{++}(0)$ ions with slow plasma electrons.

\section{Conclusions}

To summarize, it is found that a nanosecond overvoltage discharge in the air gap between the zinc or copper electrodes is a selective UV source in spectral intervals of 200-215 and 200-230 nm, respectively. The radiation emission of a discharge between the stainless steel electrodes occupies a relatively wide spectral interval of 200-300 $\mathrm{nm}$. The maximum power contribution to plasma in a pulse was $4 \mathrm{MW}$, and the energy injected into a discharge during one pulse reached a value of $0.1 \mathrm{~J}$

The most probable excitation mechanisms of UV radiation emission by atoms and ions of transition metals are the ectonic mechanism of surface erosion of metal electrodes, excitation and ionization of atoms and ions of transition metals by the electron impact, and the formation of excited metal atoms and ions in the processes of electron-ion recombination of singly and doubly charged metal ions with electrons.

The calculation of plasma parameters by numerically solving the Boltzmann equation for the electron energy distribution function showed that, in the experimental interval of reduced electric field strengths (615-820 Td), the average electron energy varies in an interval of $12.5-16.0 \mathrm{eV}$, and the electron concentration value in an interval of $(8.5 \div 10.4) \times 10^{21} \mathrm{~m}^{3}$. The excitation rate constants for the ${ }^{2} \mathrm{P}_{3 / 2,1 / 2},{ }^{2} \mathrm{D}_{3 / 2}$, ${ }^{2} \mathrm{D}_{5 / 2}$, and ${ }^{4} \mathrm{~F}_{7 / 2}$ states of copper atoms and the constants of their direct ionization by the electron impact are in intervals of $(7.4 \div 8.6) \times 10^{-13},(0.29 \div 0.28) \times$ $\times 10^{-13},(0.23 \div 0.22) \times 10^{-13},(0.20 \div 0.23) \times 10^{-15}$, and $(0.34 \div 0.45) \times 10^{-13} \mathrm{~m}^{3} / \mathrm{s}$, respectively. At $E / N=820 \mathrm{Td}$, the maximum excitation rate constant for a nitrogen molecule, $1.5 \times 10^{-14} \mathrm{~m}^{3} / \mathrm{s}$, was obtained for the set of singlet-singlet states. The specific losses of the discharge power in inelastic electron collisions with the mixture components were maximum for a nitrogen molecule; namely, $32.7 \%$ at the excitation of the set of its singlet states at $E / N=820 \mathrm{Td}$.

1. T.Kh. Bakst, V.F. Tarasenko, Yu.V. Shut'ko, M.V. Erofeev. Point-like pulse-periodic UV radiation source with a short pulse duration. Quant. Electr. 42, 153 (2012).
2. S.V. Avtaeva, O.S. Zhdanova, A.A. Pikulev, E.A. Sosnin, V.F. Tarasenko. New Direction in Scientific Research and Application of Excilamps (STT Publishing, Tomsk, 2013) [ISBN: 978-593629-xxx-x].

3. A.K. Shuaibov, G.E. Laslov, Ya.Ya. Kozak. Emission characteristics of the cathode region of nanosecond discharge in atmospheric pressure air. Opt. Spectrosk. 116, 552 (2014).

4. A.K. Shuaibov, G.E. Laslov, A.I. Minya, Z.T. Gomoki. Characteristics and parameters of nanosecond air discharge plasma between chalcopyrite electrodes. Techn. Phys. Lett. 40, 963 (2014).

5. A.K. Shuaibov, A.Y. Minya, Z.T. Gomoki, V.V. Danilo, R.B. Pinzenik. Parameters of a high-current pulse discharge in the air with the ectonic mechanism of copper vapor injection into the discharge gap. Elektr. Obrab. Nater. 54, 46 (2018) (in Russian).

6. G.A. Mesyats. Ecton or electron avalanche from metal. Phys. Usp. 38, 567 (1995).

7. A. Shuaibov, A. Minya, Z. Gomoki, R. Critzak, G. Laslov, I. Shevera. The formation of excited molecules chloride, argon, chlorine and hydroxyl radicals in the nanosecond barrier discharge. J. Electr. Engineer. 2, 96 (2014).

8. A.K. Shuaibov, R.V.Grizak. Optical characteristics of UVVUV lamps on the electronic-vibrational transitions of the hydroxyl radical, pumped by a nanosecond capacitive discharge. High. Volt. 2, 78 (2017).

9. D.V. Beloplotov, V.F. Tarasenko, D.A. Sorokin, M.I. Lomaev. Formation of spherical streamers at the subnanosecond breakdown of gases under high pressures in a nonuniform electric field. Pis'ma Zh. Eksp. Teor. Fiz. 106, 627 (2017) (in Russian).

10. D.Z. Pai, G.D. Stancu, D.A. Lacoste, Ch.O. Laux. Nanosecond repetitively pulsed discharges in air at atmospheric pressure, the glow regime. Plasma Sourc. Sci. Technol. 18, 045030 (2009).

11. D.Z. Pai, D.A. Lacoste, Ch.O. Laux. Nanosecond repetitively pulsed discharges in air at atmospheric pressure, the spark regime. Plasma Sourc. Sci. Technol. 19, 065015 (2010).

12. R.M. Van der Horst, T. Verreycken, E.M. van Veldhuizen, P.J. Bruggerman. Time-resolved optical emission spectroscopy of nanosecond pulsed discharges in atmospheric pressure $\mathrm{N}_{2}$ and $\mathrm{N}_{2} / \mathrm{H}_{2} \mathrm{O}$ mixtures. J. Phys. D 45, 345201 (2012).

13. J.M. Palomares, A. Kohut, G. Galbacs, R. Engeln, Zs. Geretovszky. A time-resolved imaging and electrical study on a high current pressure, atmospheric pressure, spark discharge. J. Appl. Phys. 118, 233305 (2015).

14. K.A. Prilepa, A.V. Samusenko, Yu.K. Stishkov. Methods for the calculation of the breakdown voltage for air gaps in weakly and strongly nonuniform fields. Teplofiz. Vys. Temp. 54, 693 (2016) (in Russian). 
15. F.G. Rutberg, V.V. Gusarov, V.A. Kolikov, I.P. Voskresenskaya et al. Research of physico-chemical properties of nanoparticles obtained using pulsed electric discharges in water. Zh. Tekhn. Fiz. 82, 33 (2012) (in Russian).

16. M. Laroussi, X. Lu, M. Keidar. Perspective: The physics, diagnostics, and applications of atmospheric pressure low temperature plasma sources used in plasma medicine. J. Appl. Phys. 122, 020901(2017).

17. E.V. Parkevich, S.I. Tkachenko, A.V. Agafonov, A.R. Mangaleev et al. Research of the prebreakdown stage of a gas discharge in a diode with a point cathode making use of laser probing. Zh. Èksp. Teor. Fiz. 151, 627 (2017) (in Russian).

18. E.V. Parkevich, A.I. Khir'yanova, A.V. Agafonov, S.I. Tkachenko et al. Peculiarities in the formation of anode plasma at the early stage of nanosecond discharge in air. Zh. $\grave{E} k s p$. Teor. Fiz. 153, 504 (2018) (in Russian).

19. V.M. Gradov, I.A. Zhelaev, S.S. Korobkov, M.V. Filippov. Ultraviolet radiation emission of pulse-periodic highpressure discharges in xenon. Matem. Matem. Model. 6, 54 (2017) (in Russian).

20. A. Bataller, J. Koulakis, S. Pree, S. Putterman. Nanosecond high-power dense microplasma switch for visible light. Appl. Phys. Lett. 105, 223501 (2014).

21. V.F. Tarasenko. Runaway Electrons Preionized Diffuse Discharge (Nova Science Publ., 2014) [ISBN: 163321883X, 9781633218833].

22. D. Levko, S. Yatom, V. Vekselman, Ya. E. Krasik. Electron emission mechanism during the nanosecond high-pressure pulsed discharge in pressurized air. Appl. Phys. Lett. 100, 084105 (2012).

23. D. Levko. Electron kinetics in a microdischarge in nitrogen at an atmospheric pressure. J. Appl. Phys. 114, 223302 (2013).

24. D. Levko, L.L. Raja. Early stage time evolution of a dense nanosecond microdischarge used in fast optical switching applications. Phys. Plasmas 22, 123518 (2015).

25. O.K. Shuaibov. Multi-Electrode Corona Discharge in Gases under High Pressure (Goverla, 2015) (in Ukrainian).

26. O.Y. Minya, O.K. Shuaibov, Z.T. Gomoki, V.V. Danilo et al. Optical parameters of nanosecond discharge in the mixture of air and zinc vapor. Visn. Uzhgorod. Univ. Fiz. 39, 93 (2016) (in Ukrainian).

27. O.K. Shuaibov, O.Y. Minya, Z.T. Gomoki, V.V. Danilo. Windowless, Point-Source, Ultraviolet Lamp. Utility model patent U 2016 04596, 10.11.2016, Bull. No. 21.

28. E.D. Kurbanov, A.V. Gorin. Glow regions of nanosecond pulse discharge in the atmospheric air at various potential electrode configurations. Upravl. Tekhnol. Pokryt. 9, 12 (2009) (in Russian).

29. L.P. Babich, T.V. Loiko, V.A. Zukerman. High-voltage nanosecond discharge in dense gases at large overvoltages developing in the runaway electron mode. Usp. Fiz. Nauk 160, 49 (1990) (in Russian).

30. V.F. Tarasenko, S.I. Yakovlenko. Electron runaway mechanism in dense gases and formation of powerful subnanosecond electron beams. Usp. Fiz. Nauk 174, 953 (2004) (in Russian).

31. E.Kh. Baksht, A.G. Burachenko, M.I. Lomaev, A.N. Panchenko et al. Source of pulse-periodic UV radiation on the basis of volume discharge initiated in nitrogen by a beam of electron avalanches. Kvant. Elektron. 45, 366 (2015) (in Russian).

32. A.V. Kozyrev, V.Yu. Kozhevnikov, I.D. Kostyrya, D.V. Rybka et al. Radiation emission of diffuse corona discharge in atmospheric pressure air. Opt. Atmos. Okean. 24, 1009 (2011) (in Russian).

33. D.V. Rybka, A.G. Burachenko, V.Yu. Kozhevnikov, A.V. Kozyrev, V.F. Tarasenko. Corona discharge in atmospheric pressure air at the modulated voltage pulse. Opt. Atmos. Okean. 27, 311 (2014).

34. V.F. Tarasenko, E.Kh. Baksht, A.G. Burachenko, M.I. Lomaev. Characteristic radiation of nitrogen at subnanosecond breakdown in a highly nonuniform electric field at the positive electrode polarity. Prikl. Fiz. 4, 49 (2016) (in Russian).

35. P.L. Smith, C. Heise, J.R. Esmond, R.L. Kurucz. Atomic Spectral Line Database from CD-ROM 23 of R.L. Kurucz (Smithsonian Astrophys. Observatory, 1995).

36. A.R. Striganov, N.S. Sventitskii. Tables of Spectral Lines of Neutral and Ionized Atoms (IFI/Plenum, 1968).

37. S.I. Maksimov, A.V. Kretinina, N.S. Fomina, L.N. Gall'. Combined radiator for spectrophotometers in a spectral interval from 200 to $1100 \mathrm{~nm}$. Nauchn. Priborostr. 25, 36 (2015) (in Russian).

38. V.I. Tyutyunnikov. Spectra of $\mathrm{ZnO}$ superdispersed particles polarized in an electric field. East. Eur. J. Phys. 2, 64 (2015).

39. E. Kh. Baksht, V.F. Tarasenko, Yu.V. Shut'ko, M.V. Erofeev. Point source of UV radiation with a frequency of $1 \mathrm{kHz}$ and a short pulse duration. Izv. Vyssh. Ucheb. Zaved. Fiz. 11, 91 (2011) (in Russian).

40. V.S. Kurbanismailov, O.A. Omarov, G.B. Rakhimkhanov, M.A. Arslanbekov, Kh.M. Abakarova, Ali Rashid Abbs Ali. Optical radiation emission of a pulsed volume discharge in high-pressure He. Usp. Prikl. Fiz. 2, 234 (2014) (in Russian).

41. A.N. Gomonai. Radiative decay of autoionizing np 2-states during dielectronic recombination of $\mathrm{Zn}^{+}$and $\mathrm{Cd}^{+}$ions. J. Appl. Spectr. 82, 17 (2015).

42. A.K. Shuaibov, A.Y. Minya, A.A. Malinina, A.N. Malinin, V.V. Danilo, M.Yu. Sichka, I.V. Shevera. Synthesis ofcopper oxides nanostructures by an overstressed nanosecond displacement in atmospheric pressure air between copper electrodes. Am. J. Mech. Mater. Eng. 2, 8 (2018).

ISSN 2071-0194. Ukr. J. Phys. 2018. Vol. 63, No. 9 
43. A.S. Pashchina, A.V. Efimov, V.F. Chinnov. Optical researches of multicomponent plasma of capillary discharge. Supersonic efflux mode. Teplofiz. Vys. Temp. 55, 669 (2017) (in Russian).

44. http: /www.bolsig.laplace.univ-tlse.fr.

45. R.V. Semenyshin, A.N. Veklich, I.L. Babich, V.F. Boretskij. Spectroscopy peculiarities of the thermal plasma of electric arc discharge between electrodes with $\mathrm{Zn}$ admixtures. Adv. Space Res. 54, 1235 (2014).

46. M.I. Lomaev, D.V. Beloplotov, D.A. Sorokin, V.F. Tarasenko. Spectral and amplitude-time characteristics of the radiation of a repetitively pulsed discharge initiated by runaway electrons, Opt. Spectrosc. 120, 171 (2016).

Received 04.04.18, Translated from Ukrainian by O.I. Voitenko
О.К. Шуаібов, А.Й. Міня, М.П. Чучман,

А.О. Малініна, О.М. Малінін, В.В. Данило, З.Т. Гомокі

ХАРАКТЕРИСТИКИ І ПАРАМЕТРИ

ПЛАЗМИ ПЕРЕНАПРУЖЕНОГО НАНОСЕКУНДНОГО РОЗРЯДУ В ПОВІТРІ 3 МАЛИМИ ДОМШШКАМИ

\section{ПАРІВ ПЕРЕХІДНИХ МЕТАЛІВ}

$\mathrm{P}$ е $з$ ю м е

Досліджено характеристики перенапруженого наносекундного розряду в повітрі коли віддаль між електродами складає (1-5) $10^{-3}$ м та при умовах внесення парів матеріалу електродів ( $\mathrm{Zn}, \mathrm{Cu}, \mathrm{Fe})$ в плазму за рахунок ектонного механізму. Шляхом числового моделювання розряду в системі "повітря-пари міді" встановлено параметри плазми розряду в залежності від величини відношення $E / N$, де $E$ - напруженість електричного поля, $N$ - концентрація частинок в розряді. 